\title{
PENGARUH ONE DIRECTION PRE-TENSION PADA REINFORCEMENT FIBRE TERHADAP KEKUATAN TARIK DAN IMPACT FIBRE-POWDER REINFORCEMENT HYBRID COMPOSITE
}

\author{
Gilang Gumilar, Tjuk Oerbandono, Bayu Satria Wardhana \\ Jurusan Teknik Mesin, Fakultas Teknik, Universitas Brawijaya \\ Jl. Mayjen Haryono 167, Malang 65145, Indonesia \\ E-mail :gilanggumilar.ub@gmail.com
}

\begin{abstract}
Nowadays, industrial manufacturing needs environmentally and friendly material and has special properties which are difficult to obtain from the metal material. Composite is one of the alternative materials that can be used to meet those needs. A structural composite material consisting of a combination of two or more elements bonded material at the macroscopic level. This study was conducted to determine the effect of pre-tension one direction on a hybrid composite reinforcement against tensile strength and impact strength. Composite materials prepared by $C$-Glass fiber types woven rovings, coconut shell powder and vinyl ester resin. manufacturing composite using hand lay-up methods. The variation of the tension given $0 \mathrm{~N}, 50 \mathrm{~N}$, $100 \mathrm{~N}, 150 \mathrm{~N}$, and $200 \mathrm{~N}$. A tensile test based on the reference standard ASTM D 3039 while testing the impact based on ASTM D 6110-04. The results were obtained giving tension to the hybrid composite reinforcement increases tensile strength and impact strength of the material. The lowest tensile strength of the composite obtained in $\mathrm{ON}$ treatment (without treatment) ranged $71,58 \mathrm{~N} / \mathrm{mm}^{2}$, and the greatest tensile strength is obtained in the pre-tension $200 \mathrm{~N}$, ranging from $106.05 \mathrm{~N} / \mathrm{mm}^{2}$. As for the lowest impact on specimens obtained without treatment ranges $1,34 \mathrm{~J}$ $/ \mathrm{mm}^{2}$ and provision of pre-tension $200 \mathrm{~N}$ biggest impact strength values obtained, ranging $15,09 \mathrm{~J}$ $/ \mathrm{mm}^{2}$
\end{abstract}

Keywords: composite, pre-tension, coconut shell, vinyl ester, tensile strength, impact strength

\section{PENDAHULUAN}

Dalam industri manufaktur dibutuhkan material yang memiliki sifat-sifat istimewa yang sulit didapat dari logam. Komposit merupakan material alternatif yang dapat digunakan untuk memenuhi kebutuhan tersebut. Namun, penggunaan serat sintetik dalam pembuatan komposit saat ini banyak menimbulkan masalah yang cukup serius bagi lingkungan sehingga industri mulai beralih menggunakan serat alam (natural fiber) karena sifatnya yang lebih ramah lingkungan, disamping ketersediaan serat alam yang sangat melimpah dan pemanfaatannya sampai saat ini masih belum optimal [1].

Tuntutan kebutuhan bahan teknik dewasa ini semakin tinggi baik bahan logam maupun non logam.Pengetahuan ilmu bahan memegang peranan yang sangat penting dalam dunia industri, terutama industri yang bergerak dalam bidang manufaktur.Dimana lebih dari $60 \%$ harga pokok penjualan atau biaya produksi berasal dari komponen material.Perkembangan teknologi material telah melahirkan suatu material jenis baru yang dibangun secara bertumpuk dari beberapa lapisan. Material inilah yang disebut material komposit [2].

Agus Hariyanto (2008) meneliti karakteristik komposit tempurung kelapa bermatrik epoxyditinjau dari aspek kekuatan tarik dan impak untuk mengetahui sifat mekanik komposit terhadap kekuatan tarik dan kekuatan impak. Hasil penelitian ini menunjukkan bahwa pertambahan fraksi volume dan diameter partikel serbukj kelapa menurunkan kekuatan tarik.namun meningkatkan kekuatan impact [3].

Praisy (2014) meneliti pengaruh penarikan mula satu arah pada reinforcement fiber panel terhadap kekuatan tarik. Dari penelitian tersebut didapatkan kesimpulan bahwa penambahan nilai tarikan satu arah (one direction tension) pada reinforcement fiber berpengaruh positif terhadap nilai kekuatan tarik komposit. Tension yang diberikan adalah $0 \mathrm{~N}, 5 \mathrm{~N}, 10 \mathrm{~N}, 15 \mathrm{~N}$ dan $20 \mathrm{~N}$. Dimana semakin besar beban pre-tension pada komposit maka kekuatan tariknya cenderung meningkat [4]. 
Pada penelitian ini peneliti ingin meneliti pengaruh pemberian one direction pre-tension pada reinforcement hybrid composite dan diharapkan dapat meningkatkan kekuatan tarik dan kekuatan impact material. Bahan yang digunakan pada penelitian ini diantaranya dengan bahan penguat serat c-glass dan serbuk tempurung kelapa dengan besar partikel 80 mesh serta resin vinylester sebagai matriksnya.

Serat gelas yang digunakan pada penelitian ini berjenis anyaman (woven roving) seperti pada Gambar 1. Serat jenis ini mempunyai bentuk seperti anyaman tikar yang dibuat saling bertindih secara selang seling sehingga dapat menyalurkan beban secara lebih merata ke arah vertikal dan horisontal $\left(0^{\circ}\right.$ dan $\left.90^{\circ}\right)$.

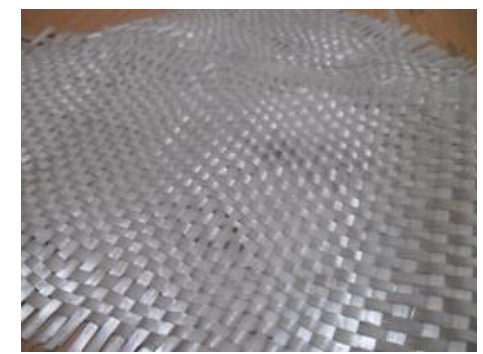

Gambar 1. Serat gelas anyaman

Serat gelas (glass fiber) adalah bahan yang tidak mudah terbakar.Serat jenis ini biasanya digunakan sebagai penguat matrik jenis polimer. Komposisi kimia serat gelas sebagain besar adalah $\mathrm{SiO}$ dan sisanya adalah oksida-oksida alumunium (Al), kalsium (Ca), magnesium $(\mathrm{Mg})$, natrium $(\mathrm{Na})$, dan unsurunsur lainnya ${ }^{[8]}$. Berdasarkan bentuknya serat gelas dapat dibedakan menjadi beberapa macam antara lain.

Tempurung kelapa terletak dibagian didalam buah kelapa setelah sabut. Tempurung ini merupakan lapisan yang keras dengan ketebalan antara $3-5 \mathrm{~mm}$. sifat kerasnya disebabkan oleh kandungan silikat $\left(\mathrm{SiO}_{2}\right)$ yang terdapat pada tempurung tersebut. Prosentase tempurung kelapa berkisar antara 15\% - 19\% dari total berat buah kelapa [5]. Pada penelitian ini tempurung kelapa digiling dan disaring dengan saringan bercelah 80 mesh sehingga berbentuk partikel seperti Gambar 2.

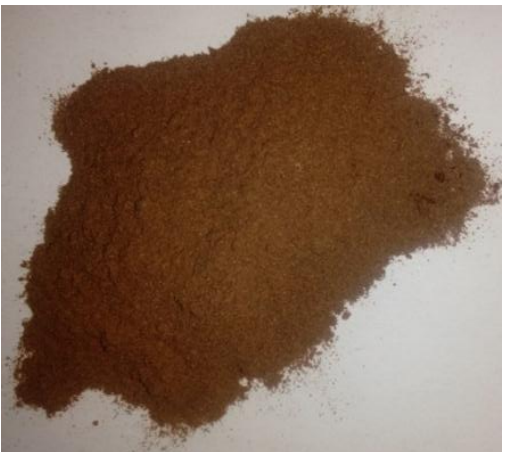

Gambar 2. Serbuk tempurung kelapa

Vinyl Ester, atau vinylester, adalah resin yang dihasilkan oleh esterifikasi suatu resin epoksi dengan asam monokarboksilat jenuh. Resin jenis ini memiliki workability yang baik seperti polyester resin, karakteristik kekuatan dan ketahanan kimia yang baik [6].

\section{METODOLOGI PENELITIAN}

Metode yang digunakan dalam penelitian ini adalah eksperimental nyata (True Experimental Research), yang bertujuan untuk mengetahui pengaruh one direction pre-tension pada reinforcement hybrid composite terhadap kekuatan tarik dan kekuatan impact.

Pembuatan spesimen dilakukan dengan metode hand lay up seperti pada Gambar 3. Metode ini merupakan cara yang paling sederhana karena dapat dilakukan menggunakan alat sederhana. Pada metode ini serat yang telah diletakkan pada cetakan kemudian dilapisi dengan resin/matriks yang dituang dan di ratakan menggunakan roller agar matriks memenuhi celah yang ada secara merata.

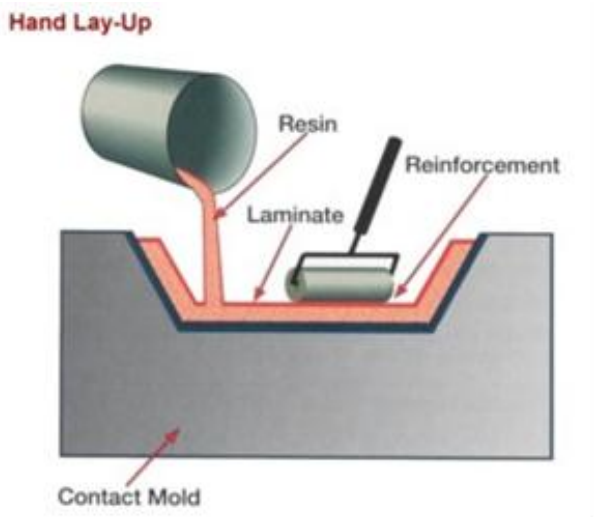

Gambar 3. Metode hand lay up 
Setelah spesimen jadi kemudian dilakukan pengujian kekuatan tarik dan pengujian impact untuk memperoleh hasil kekuatan material.

Pengujian tarik dilakukan dengan mesin uji tarik atau dengan universal testing machine menurut standar ASTM D 3039. Untuk mendapatkan nilai kekuatan tarik dapat dicari dengan rumus :

$$
\sigma_{\mathrm{u}}=\frac{P_{\max }}{A_{u}}
$$

Dimana:

$\sigma_{\mathrm{t}} \quad=$ Kekuatan tarik ultimate $\left(\mathrm{N} / \mathrm{mm}^{2}\right)$

$\mathrm{P}_{\max } \quad=$ Beban tarik maksimum $(\mathrm{N})$

$\mathrm{A}_{u} \quad=$ Luas penampang saat patah $\left(\mathrm{mm}^{2}\right)$

Untuk pengujian impact dilakukan dengan standar pengujian ASTM D6110-04. Perhitungan mencari kekuatan impact spesimen berdasarkan ASTM D6110-04 adalah sebagai berikut:

$$
\begin{aligned}
\mathrm{E}= & \operatorname{Pd}\left[(\cos \beta-\cos \alpha)-\left(\cos \alpha^{\prime}-\right.\right. \\
& \cos \alpha)\left(\alpha+\beta / \alpha+\alpha^{\prime}\right)
\end{aligned}
$$

Dimana:

$\mathrm{E} \quad$ = energi yang diserap setelah tumbukan (J)

$\mathrm{Pd}=$ pendulum momen $(\mathrm{Nm})$

$\alpha \quad=$ sudut akhir $\left({ }^{\circ}\right)$

$\alpha^{\prime} \quad=$ sudut pendulum tanpa beban $\left({ }^{\circ}\right)$

$\beta=$ sudut akhir aktual $\left(^{\circ}\right)$

\section{VARIABEL PENELITIAN}

1. Variabel Bebas

Variabel bebas adalah variabel yang besarnya ditentukan sebelum penelitian. Dalam penelitian ini variabel bebas yang digunakan adalah besarnya pre-tension sebesar $0 \mathrm{~N}, 50 \mathrm{~N}$, $100 \mathrm{~N}, 150 \mathrm{~N}$, dan $200 \mathrm{~N}$.

2. Variabel terikat

Variabel terikat adalah variabel yang besarnya tergantung pada variabel bebas.Dalam penelitian ini variabel terikatnya adalah kekuatan tarik dan impact.

3. Variabel terkontrol

Variabel terkontrol adalah variabel yang besarnya dikonstantakan. Dalam hal ini yang menjadi variabel terkontrol adalah
- Prosentase Serbuk kelapa 20\% dari volume material

- Prosentasi katalis $2.5 \%$ dari volume matrik.

- Jumlah serat reinforcement fiber longitudinal $=4$

- Jumlah serat reinforcement fiber transversal $=62$

- $\quad$ Curing menggunakan suhu ruang.

Pemberian pre-tension dilakukan secara satu arah secara longitudinal, diilustrasikan pada Gambar 4.

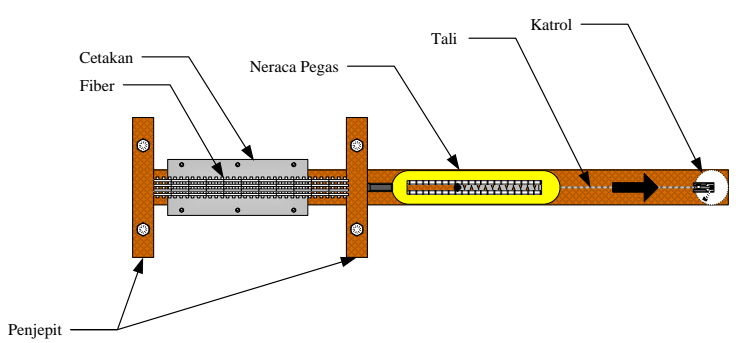

Gambar 4. Ilustrasi pre-tension

\section{HASIL DAN PEMBAHASAN}

- Pengujian Tarik

Dari hasil pengujian tarik diperoleh nilai

\begin{tabular}{|c|c|c|c|c|c|}
\hline \multirow{3}{*}{$\begin{array}{l}\text { Pengu- } \\
\text { langan }\end{array}$} & \multicolumn{5}{|c|}{ Tension (N) } \\
\hline & \multicolumn{5}{|c|}{$\mathrm{F} 0=0 \mathrm{~F} 1=50 \mathrm{~F} 2=100 \mathrm{~F} 3=150 \mathrm{~F} 4=200$} \\
\hline & \multicolumn{5}{|c|}{ Kekuatan Tarik (N/mm²) } \\
\hline 1 & 70.55 & 99.57 & 86.86 & 104.12 & 114.72 \\
\hline 2 & 73.69 & 75.92 & 102.35 & 84.38 & 100.85 \\
\hline 3 & 70.51 & 70.91 & 77.29 & 122.03 & 102.59 \\
\hline Jumlah & 214.75 & 246.40 & 266.50 & 310.53 & 318.16 \\
\hline Rata-rata & 71.58 & 82.13 & 88.83 & 103.51 & 106.05 \\
\hline
\end{tabular}
kekuatan tarik spesimen pada Tabel1.

Tabel 1. Data hasil pengujian tarik

Berdasarkan Tabel 1 ketika tidak diberikan perlakuan (pre-tension) nilai kekuatan tarik komposit berkisar $71,58 \mathrm{~N} / \mathrm{mm}^{2}$, dengan perlakuan pre-tension $50 \mathrm{~N}$ nilai keuatan tariknya menjadi berkisar $82,13 \mathrm{~N} / \mathrm{mm}^{2}$, pemberian pre-tension $100 \mathrm{~N}$ nilai kekuatan tariknya berkisar $88,83 \mathrm{~N} / \mathrm{mm}^{2}$, pemberian pretension $150 \mathrm{~N}$ nilai kekuatan tariknya berkisar $103,51 \mathrm{~N} / \mathrm{mm}^{2}$, dan pemberian pre-tension $200 \mathrm{~N}$ nilai kekuatan tariknya berkisar 106,05 
$\mathrm{N} / \mathrm{mm}^{2}$. Berdasarkan data hasil penelitian uji tarik pada tabel 1 dilakukan perbandingan terhadap pre-tension.

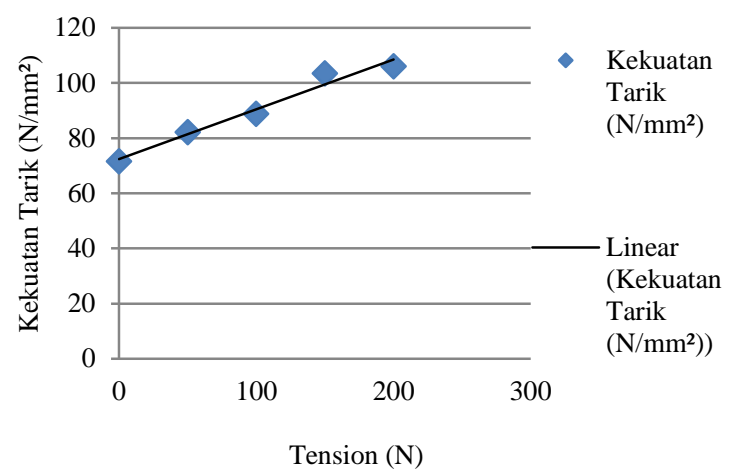

Gambar 5. Grafik pengaruh pre-tension terhadap kekuatan tarik

Berdasarkan Gambar 5 dapat dilihat bahwa pemberian pre-tension pada pembentukan komposit berpengaruh terhadap kekuatan tariknya.Hasil pengujian tersebut menunjukkan bahwa pemberian pre-tension satu arah pada serat dalam pembuatan komposit hibrid meningkatkan kekuatan tarik komposit. Hal tersebut terjadi dikarenakan ketika serat ditarik dengan gaya tertentu maka posisi serat akan cenderung liniear mengikuti arah tarikan (searah dengan panjang serat) dan berdeformasi elastis. Sehingga saat resin mengering dan gaya tarik dilepas maka terdapat gaya balik dari serat yang mengikuti arah penyusutan resin sehingga memperkecil tegangan sisa pada komposit.

- Pengujian Impact

Dari hasil pengujian tarik diperoleh nilai kekuatan impact spesimen pada Tabel 2.

Tabel 2. Data hasil pengujian impact

\begin{tabular}{cccccc}
\hline \multirow{2}{*}{$\begin{array}{c}\text { Pengu- } \\
\text { langan }\end{array}$} & \multicolumn{5}{c}{ Tension (N) } \\
\cline { 2 - 6 } & $F 0=0$ & $F 1=50$ & $\begin{array}{c}F 2= \\
100\end{array}$ & $F 3=150=4=200$ \\
\cline { 2 - 6 } & \multicolumn{5}{c}{ Kekuatan Impact $\left(\mathrm{J} / \mathrm{mm}^{2}\right)$} \\
\hline 1 & 0.46 & 4.55 & 16.28 & 16.28 & 12.71 \\
\hline 2 & 2.00 & 11.99 & 3.80 & 16.28 & 16.28 \\
\hline 3 & 1.57 & 4.55 & 11.99 & 3.80 & 16.28 \\
\hline Jumlah & 4.02 & 21.08 & 32.07 & 36.36 & 45.26 \\
\hline Rata-rata & 1.34 & 7.03 & 10.69 & 12.12 & 15.09 \\
\hline
\end{tabular}

Dari Gambar 6 dapat dilihat nilai kekuatan impact terendah diperoleh komposit tanpa diberikan pre-tension yaitu sebesar $1,34 \mathrm{~J} / \mathrm{mm}^{2}$. Nilai kekuatan impact komposit cenderung meningkat ketika diberikan pre-tension dengan tarikan yang semakin besar pula dengan nilai kekuatan impact tertinggi dicapai oleh spesimen yang diberikan pre-tension $200 \mathrm{~N}$ yaitu sebesar $15,09 \mathrm{~J} / \mathrm{mm}^{2}$

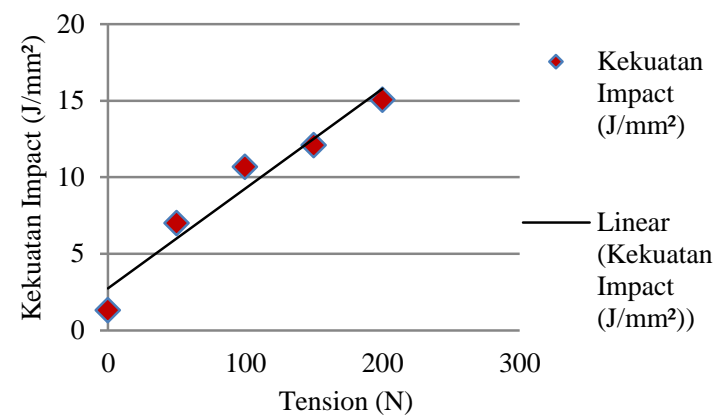

Gambar 6. Grafik pengaruh pre-tension terhadap kekuatan impact

Berdasarkan Gambar 6 dapat dilihat pengaruh pre-tension terhadap kekuatan tarik komposit meningkatkan kekuatan impact.Dari hasil pengamatan pada saat pengujian spesimen yang diberikan perlakuan pre-tension bahwa ketika diberikan impact pada pendulum spesimen mengalami kerusakan tetapi serat yang terdapat pada komposit tidak putus dan masih menyatu dengan spesimen.Dari Gambar 7 dapat dilihat bahwa serat masih menghubungkan specimen setelah diberi impact. Hal ini terjadi karena jika serat ditarik dengan gaya tarik yang semakin besar maka kondisi celah pada serat tersebut semakin mengecil sehingga resin akan sulit untuk membasahi serat bagian dalam, sehingga hanya bagian serat terluar yang menyatu dengan resin setelah resin mengering. Dengan kata lain kekuatan yang dihasilkan komposit lebih mendekati kekuatan seratnya.

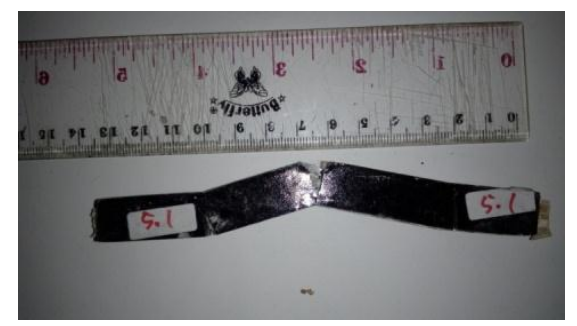

Gambar 7. Patahan spesimen impact 


\section{KESIMPULAN}

Dari hasil pengujian dan analisis data dapat ditarik kesimpulan bahwa pemberian one direction pre-tension pada reinforcement hybrid composite dapat meningkatkan kekuatan tarik dan impact komposit. Kekuatan tarik dan impact komposit terendah didapat pada spesimen tanpa perlakuan pre-tension yaitu sebesar $71,58 \mathrm{~N} / \mathrm{mm}^{2}$ untuk kekuatan tarik dan $1,34 \mathrm{~J} / \mathrm{mm}^{2}$ untuk kekuatan impact. Sedangkan nilai kekuatan tarik dan kekuatan impact diperoleh pada spesimen dengan perlakuan pre-tension $200 \mathrm{~N}$, yaitu sebesar 106,05 N/mm² untuk kekuatan tarik dan 15,09 $\mathrm{J} / \mathrm{mm}^{2}$.

\section{DAFTAR PUSTAKA}

[1] Autar. (2006). Mechanics of Composite Material. New York: Taylor and Francis Inc.
[2] Mazumdar. (2002). Composites Manufacturing. New York: CRC Press LLC.

[3] Haryanto, Agus. (2008). Pengaruh Perlakuan Alkali pada Rekayasa Bahan Komposit Berpenguat Serat Rami Bermatrik Poliester terhadap Kekuatan Mekanis

[4] Kastanja, P. M. (2014). PengaruhVariasi Tarikan Satu Arah (One Direction Tension) pada Reinforcement Fiber Panel Komposit Datar Terhadap Kekuatan Tarik.

[5] Pangkulun, R. (1999). Aneka Produk Olahan Kelapa. Bogor: Penebar Swadaya.

[6] Showa Denko K.K. (n.d.). Ripoxy Data Sheet. 